\title{
Some Factors Associated with Ovarian Disorders of Dairy Cattle in Northern Vietnam
}

\author{
S. T. Long ${ }^{\mathrm{a}, *}$, P. V. Gioi ${ }^{\mathrm{b}}, \&$ N. T. Suong ${ }^{\mathrm{c}}$ \\ aVietnam National University of Agriculture, Ha Noi 100000, Viet Nam \\ ${ }^{b}$ National Institute of Animal Science, Ha Noi 100000, Viet Nam \\ 'Biodiversity Conservation and Tropical Diseases Research Institute, Ha Noi 100000, Viet Nam \\ *Corresponding author: sulongjp@yahoo.com \\ (Received 05-06-2020; Revised 20-10-2020; Accepted 23-10-2020)
}

\begin{abstract}
This research's objectives were to assess the risk factors associated with ovarian disorders in dairy cattle in Hanoi Capital, Ha Nam Province, Vinh Phuc Province, and Moc Chau District in Son La Province. The ovarian diseases were evaluated by rectal palpation combined with information collected based on the questionnaire and surveys. Records of feeding management and ovarian disorders were comprising of persistent corpus luteum (PCL), cystic ovarian disease (COD), inactive ovary (IO) from 818 females, including heifers and cows from the first to the eighth parities. A multinomial logistic regression procedure in SAS9.0 was applied for data analysis. The results have shown that the changes of region, age classes, housing condition, and body condition scores were associated with the odds of suffering from dairy cattle's ovarian disorder categories. The cows got the odds of suffering from PCL in the old age or fatter condition, and IO at the younger or angular cows. When cattle were confined in simple houses or laid on rubber bedding, they suffered from IO, but they tended to get the odds of suffering from PCL when the cattle were raised in modern houses or laid on concrete bedding. In conclusion, region, parity, body condition score, housing type, and bedding material affect ovarian disorders in dairy cattle in northern Vietnam.
\end{abstract}

Keywords: ovarian disorder; dairy cattle; reproductive performance; logistic regression

\section{INTRODUCTION}

The dairy industry has been developing in Vietnam, in which the total dairy population and milk production are keeping on growing in recent years. High milk production and good reproductive performance in dairy cattle are always aspirations for both dairy farmers and management officials at the moment. However, dairy cows with the highest milk productions are exposed to the risk of reducing reproductive competence (Walsh et al., 2011; Santolaria et al., 2012; Alawneh et al., 2012). The ovarian disorder syndromes in dairy cows such as cysts, persistent corpus luteum, and hypofunction are major factors emerging, causing the low conception rate, prolonged calving intervals, high expenditure for insemination, and finally resulted in great economic losses in the dairy industry.

Good control of ovarian disorder should be a deterministic and possible solution for the enhancement of dairy cows' reproductive performances. However, Inchaisri et al. (2010) and Simensen et al. (2010) reported the strong effects of nutrition, feeding management, and housing types on ovarian dysfunction, reducing economic efficiency in the dairy industry. Environmental improvement is necessary to restrict their effects on fertility (Yaniz et al., 2008). However, most scientists only studied and searched therapies for the treatment of ovarian dysfunction, and so far, they have still never mentioned the related factors with ovarian dysfunctions in Vietnam (Luu et al., 2014; Long et al., 2017). Therefore, outstanding and good controlling of ovarian dysfunction on dairy cattle should be the substantial key for the development of the dairy industry in Vietnam at the moment and near future.

\section{MATERIALS AND METHODS}

\section{Dairy Cattle Herds Regions for Research}

A total of 818 female dairy cattle from heifers at the estrous age and breeding, out of which 156 heifers and 662 cows from the first to the ninth parity were assigned into three classes: parity 0 (heifers), parity 1 (the first parity), parity 2 (the second parity or over). Dairy cattle were purebred Holstein Friesian (HF), or HF crossbred with genomes equal or over $87.5 \%$ HF was kept in dairy farms of Moc Chau District, Son La Province; Vinh Tuong District, Vinh Phuc Province; Ha Nam Province; and on the peripheral zones of Hanoi Capital. 


\section{Diagnostic Method of Ovarian Diseases}

Ovaries conditions were evaluated by rectal palpation combined with the gathering of information about the cow's reproductive status from the farm information. Persistent corpus luteum (PCL) was determined when the corpus luteum (luteal tissue with a thick wall) was found on the ovarian cortex at the first time of examination in dairy cattle that did not show estrus signs even though the time period of observation was conducted more than one estrus cycles.

Cystic ovarian disease (COD) was concluded when observing the larger follicles (more than $25 \mathrm{~mm}$ in diameter) on the ovarian surface at the cow's first examination with continuous signs of estrus. In inactive ovary (IO), cows did not show heat signs during a period that exceeds the normal cycle. Ovarian examination revealed a flattened, small, and smooth appearance without CL and follicle presence.

The estrus data were not fully obtained when a double palpation examination was conducted at intervals of 7 to 10 days. The ovarian disorders were determined through the results of two palpation times according to the description of Long et al. (2017). Veterinarians performed ovarian examinations and information collection in the field of theriogenology in each study area, and all of them have experience of over 6 years. They are those who have been trained annually and have been participating in advanced training before joining this study by experts at the Vietnam National University of Agriculture and Edinburgh University, England.

\section{Data Collection}

The standard questionnaires, set up based on the actual feeding management, were completed by veterinarians and technicians with interviewed dairy farmers, storage information, and actual observations at the farms. The regions were assigned into three classes: Hanoi Capital and Ha Nam Province, Moc Chau District, Son La Province, and Vinh Phuc Province (Hanoi was matched with Ha Nam Province due to the similarity of climate and feeding conditions). Body condition scores of cattle were scored according to Marija Klopcic et al. (2011) from 2.0 (too angularity) to 4.0 (too obesity), with a scaling increment of 0.25 and assigned into three classes: BCS1 (2.0 to 2.5) - thin; BCS2 (2.75 to 3.25 ) - medium; BCS3 (3.5 to 4.0 ), cattle were obese status.

All female dairy cattle at the periods of estrus and insemination did not exhibit cyclicity and estrous exposures. The ages of heifers were from 18 months or over, and cows were in the conditions of 3 months after calving. Categories of ovarian disorder were assigned into cystic ovarian disease (COD), persistent corpus luteum (PCL), and inactive ovaries (IO) (Table 1).

The Viet Nam Animal Welfare Association assessed the experiment to ensure high welfare animal standards (Ethics Approval No: 2019-01/QĐ-VAWA on January 01, 2019). Authors have ensured validity when planning and describing animal experimental research and also met the specific requirements for conducting animal experiments in research.

\section{Data Analyses}

Procedures of multinomial logistic regression in SAS 9.0 were applied for analyzing this dataset, five multinomial logistic regression models with the single factor were used with the following common models:

$$
\begin{aligned}
& \operatorname{Logit}\left(\pi_{i}\right)=\beta_{0_{i}}+\beta_{i} F_{i}+e \\
& \operatorname{Logit}\left(\pi_{i}\right)=\ln \left(\frac{P=Y_{i}}{P=Y_{j}}\right)
\end{aligned}
$$

where Logit $(\pi)$ is Logistic function, $\beta_{0}$ is constant, $\beta$. is slope for $i^{\text {th }}$ factor, $P=Y_{i}$ is Probability of event for $i^{\text {th }}$ dependent variable, $P=Y_{j}$ is Probability of $j^{\text {th }}$ dependent variable, and it was treated as reference variable (probability of IO or COD), e is random errors.

$F_{i}$ is factor, where Model 1 is For regions: $i=3$ (Hanoi - Ha Nam, Moc Chau - Vinh Phuc), Model 2 is For parities: $\mathrm{i}=3$ (Heifers (Parity $=0$ ), first parity, second parity and over, Model 3 is For body condition score: $\mathrm{i}=3$ (BCS1, BCS2, BCS3), Model 4 is For housing type: $i=2$ (Simple house and Well-invested shed), and Model 5 is For bedding materials: $\mathrm{i}=2$ (concrete material and rubber material).

Parameters of regions, parities, body condition scores, housing type, bedding materials were treated as classes. At the same model, two runs were executed. At the first run, variable $\mathrm{IO}$ was treated as a referent variable; at the second run, COD was treated as a referent variable.

\begin{tabular}{|c|c|c|c|}
\hline Ovarian examination & $\begin{array}{l}\text { First palpation } \\
\text { Day } 1 \\
\end{array}$ & $\begin{array}{l}\text { Second palpation } \\
\text { After 7-10 days }\end{array}$ & Conclusions \\
\hline \multirow[t]{3}{*}{ Corpus lutein } & + & + & PCL \\
\hline & - & + & Normal \\
\hline & + & - & Normal \\
\hline \multirow[t]{3}{*}{ Follicle } & + & + & COD \\
\hline & - & + & Normal \\
\hline & + & - & Normal \\
\hline Follicle and Corpus lutein & - & - & $\mathrm{IO}$ \\
\hline
\end{tabular}

Table 1. Diagnostic method for ovarian diseases

Note: + = existed event; - = non-existed event; $\mathrm{PCL}=$ Persistent corpus luteum; $\mathrm{IO}=$ Inactive ovarian disease; $\mathrm{COD}=\mathrm{Cystic}$ ovarian disease. 


\section{RESULTS}

\section{The Effect of Regions on Categories of Ovarian Disorder}

The results presented in Table 2 indicated that different regions had significant effects on different categories of ovarian disorder in dairy cattle raising in the north of Vietnam. In Logit 1, the likelihood showed that the cows raised in Hanoi-Ha Nam suffered from PCL instead of IO and the number of cows suffered from PCL was significantly lower than that of cows raised in Moc Chau $(p<0.05)$. However, the number of cows raised in Hanoi-Ha Nam and in Moc Chau suffering from PCL instead of IO were significantly higher than cows raised in Vinh Phuc $(\mathrm{p}<0.05)$. The odds ratio for parameters in Logit 1 illustrated that the number of cows in Hanoi suffering from PCL instead of IO was about 0.52 times versus cows raised in Moc Chau (in the other word, the odds for the cows in Hanoi suffered from PCL was significantly lower than the cows kept in Moc Chau, i.e., about $48 \%$ ), and was about 1.75 times higher than cows in Vinh Phuc. The cows raised in Moc Chau suffered from PCL was about 3.39 times higher than cows kept in Vinh Phuc. Therefore, the dairy cattle raised in Moc Chau and Hanoi tended to get the odds of PCL, and cows in Vinh Phuc tended to get the odds of IO $(p<0.05)$.

In Logit 2, the probability values and the likelihood estimates exposed that the number of cows raised in Hanoi influenced by COD instead of IO was not significantly higher than the cows raised in Moc Chau. However, the number of cows kept in Hanoi-Ha Nam and Moc Chau suffering from COD instead of IO was significantly higher than that of cows kept in Vinh Phuc $(p<0.05)$. The estimated odds ratios showed that the number of cows raised in Hanoi that were suffered from COD instead of IO was about 1.28 times higher than the number of cows raised in Moc Chau, but the difference was not statistically significant $(p>0.05)$. The odds of cows raised in Hanoi and Moc Chau that were suffered from COD instead of IO were about 4.63 times and 3.62 times compared to cows raised in Vinh Phuc $(p<0.05)$.
Therefore, cows raised in Moc Chau and Hanoi tended to get COD, and cows in Vinh Phuc tended to get IO.

In Logit 3, the likelihood estimates were all negative, and their probabilities demonstrated that the number of cows reared in Hanoi-Ha Nam that suffered from PCL instead of COD was significantly lower than that of cows in Moc Chau and in Vinh Phuc; the cows nourished in Moc Chau had PCL instead of COD that was not significantly lower than in Vinh Phuc $(p>0.05)$. The odds ratios in Logit 3 explained that the odds of getting PCL over COD were about 0.40 times in cows raised in Hanoi versus cows in Moc Chau. However, the number of cows getting PCL instead of COD in Hanoi was 0.38 times compared to those in Vinh Phuc $(p<0.05)$. In contrast, the number of cows getting PCL instead of COD in Moc Chau was 0.94 times compared to that of Vinh Phuc, but the difference was not statistically significant $(p>0.05)$. Cattles raised in Hanoi-Ha Nam tended to get PCL instead of COD, and the incidence was lower than cattle raised in Moc Chau and Vinh Phuc.

From the above data, the results indicated that dairy cattle produced in Hanoi-Ha Nam and Moc Chau got the odds of suffering from PCL or COD, and dairy cattle reared in Vinh Phuc tended to get the odds of suffering from IO. In Hanoi-Ha Nam, cattle suffering from PCL instead of COD was 60\% lower than in Moc Chau and was $62 \%$ lower than in Vinh Phuc.

\section{The Effect of Parities}

The results of likelihood estimates are presented in Table 3. In Logit 1, the estimates were negative for Parity 0 versus Parity 2 (-0.97) and for Parity 0 versus Parity 1 (-0.82), and these findings indicated that the cows getting PCL instead of IO were significantly lower when they were in Parity 0, or when they were heifers $(\mathrm{p}<0.05)$. The estimate was -0.15 of Parity 1 versus Parity 2, showing that PCL's risk instead of IO was not statistically significant between Parity 1 and Parity 2 . Therefore, the cows suffering from PCL were higher when they were older ages. When the females were younger, they mostly dominated by suffering from IO.

Table 2. Maximum likelihood estimates and odds ratio of variables of different regions on categories of ovarian disorders (with referent dependent variables as IO and COD in the analyzed models)

\begin{tabular}{|c|c|c|c|c|c|c|c|c|c|c|}
\hline \multirow{3}{*}{ Logits } & \multirow{3}{*}{ Variables } & \multicolumn{4}{|c|}{ Maximum likelihood estimates } & \multicolumn{4}{|c|}{ Odds ratio } & \multirow{3}{*}{$\begin{array}{c}\mathrm{Pr}> \\
\text { ChiSq }\end{array}$} \\
\hline & & \multirow{2}{*}{ Est } & \multirow{2}{*}{$\mathrm{SE}$} & \multicolumn{2}{|c|}{ CL95\% } & \multirow{2}{*}{$\begin{array}{l}\text { Odds } \\
\text { ratio }\end{array}$} & \multirow{2}{*}{$\mathrm{SE}_{\text {Odds }}$} & \multicolumn{2}{|c|}{ CL95\% } & \\
\hline & & & & Lower & Upper & & & Lower & Upper & \\
\hline \multirow{3}{*}{$\begin{array}{c}1 \\
(\mathrm{PCL} / \mathrm{IO})\end{array}$} & $\mathrm{HN}$ vs MC & -0.66 & 0.22 & -1.1 & -0.22 & 0.52 & 0.12 & 0.33 & 0.8 & 0.0033 \\
\hline & HN vs VP & 0.56 & 0.19 & 0.2 & 0.93 & 1.75 & 0.33 & 1.22 & 2.53 & 0.0025 \\
\hline & MC vs VP & 1.22 & 0.2 & 0.84 & 1.61 & 3.39 & 0.67 & 2.31 & 4.98 & $<.0001$ \\
\hline \multirow{3}{*}{$\begin{array}{c}2 \\
(\mathrm{COD} / \mathrm{IO})\end{array}$} & $\mathrm{HN}$ vs MC & 0.25 & 0.3 & -0.34 & 0.84 & 1.28 & 0.39 & 0.71 & 2.32 & 0.4125 \\
\hline & HN vs VP & 1.53 & 0.27 & 1.01 & 2.05 & 4.63 & 1.23 & 2.75 & 7.79 & $<.0001$ \\
\hline & MC vs VP & 1.29 & 0.31 & 0.67 & 1.9 & 3.62 & 1.13 & 1.96 & 6.67 & $<.0001$ \\
\hline \multirow{3}{*}{$\begin{array}{c}3 \\
\text { (PCL/ } \\
\text { COD) }\end{array}$} & $\mathrm{HN}$ vs MC & -0.91 & 0.29 & -1.47 & -0.34 & 0.4 & 0.12 & 0.23 & 0.71 & 0.0018 \\
\hline & HN vs VP & -0.97 & 0.27 & -1.51 & -0.44 & 0.38 & 0.1 & 0.22 & 0.65 & 0.0004 \\
\hline & MC vs VP & -0.06 & 0.31 & -0.66 & 0.53 & 0.94 & 0.29 & 0.52 & 1.71 & 0.8335 \\
\hline
\end{tabular}

Note: $\mathrm{PCL}=$ Persistent corpus luteum; $\mathrm{IO}=$ Inactive ovarian disease; $\mathrm{COD}=\mathrm{Cystic}$ ovarian disease; $\mathrm{HN}=\mathrm{Hanoi}-\mathrm{Ha} \mathrm{Nam}, \mathrm{VP}=\mathrm{Vinh} \mathrm{Phuc}, \mathrm{MC}=\mathrm{Moc}$ Chau-SonLa; $\mathrm{SE}=$ Standard errors of likelihood estimates; $\mathrm{SE}_{\mathrm{Odds}}=$ Standard errors of estimated odds rasio; CL95\%= Confident limits $95 \%$. 
The odds ratio of Parity 0 versus Parity 2 was 0.38 , illustrating that the heifers suffered from PCL instead of IO was equal to 0.38 times over cows at Parity 2 and was equal to 0.44 times versus Parity 1 . Therefore, the odds for suffering from PCL instead of IO was about 2.27 times higher for these cows when they were in Parity 1 compared to in heifers age, and were about 2.64 times higher when they were in Parity 2 compared to in heifers age, or when they changed from heifers to Parity 1 or Parity 2. The odds ratio at Parity 1 versus Parity 2 was 0.86 , showing that the cows at Parity 1 had PCL 0.86 times compared to Parity 2, but it was not statistically significant $(\mathrm{p}>0.05)$. These results also indicated that when they were at a young age, the ovarian disorder was tended to be $\mathrm{IO}$, and at an older age, the disorder was tended to be PCL.

For Logit 2, the results showed that all estimates were negative and their probabilities were greater than the significant level of 0.05 , which gives evidence that the changes in parities do not affect the risk of COD versus IO for the dairy cattle.

Similarly, at Logit 3, the likelihood estimates for Parity 0 versus Parity 1 , and Parity 0 versus Parity 2 were negative, and their probabilities were all less than the significant level of 0.05 . These indicate that the cows suffering from PCL instead of COD were significantly lower when they were in Parity 0 (Heifers) versus when they were in Parity 1 and Parity 2. When the cows got older, they tended to get PCL instead of COD, and when they were heifers, they tended to get COD instead of PCL. The odds ratios for Parity 0 versus Parity 1 and Parity 2 were statistically significant, and these results showed that the heifers suffered from PCL instead of COD was 0.42 times compared to the cows in Parity 1 and was 0.51 times compared to the cows in Parity 2. Therefore, the cows in Parity 1 that suffered from PCL were about 2.40 times higher than heifers, and the cows in Parity 2 suffered from PCL were about 1.95 times higher than heifers. However, cows that suffered from PCL instead of COD were 1.23 times when they were in Parity 1 versus Parity 2, but this odds ratio was not statistically significant $(p>0.05)$. It may be concluded that heifers suffering from PCL were lower and suffered from COD were higher, but the old cows suffering from PCL were higher and suffered from COD were lower, and PCL was dominant in Parity 1.

\section{The Effects of Body Condition Scores}

The likelihood estimates and odds ratio values of parameters of different Body condition scores on categories of ovarian disorders are shown in Table 4. For Logit 1, the values of likelihood estimates were negative: -0.90 at BCS1 versus BCS3; -1.21 at BCS2 versus BCS3, indicating that the cows suffering from PCL instead of IO were significantly lower when their body condition scores changed from BCS3 to BCS2 or BCS1 $(\mathrm{p}<0.05)$. When cattle got more angular (thinner), they would get $\mathrm{IO}$, and when they got fatter, they tended to get PCL. But the likelihood estimates were the positive value of 0.31 at BCS1 versus BCS2, and this result indicated that when the cows moved from BCS2 to BCS1 (cows get thinner), they would suffer from PCL instead of IO, but it was not significantly higher $(\mathrm{p}>0.05)$.

For Logit 2, the values of likelihood estimates were also negative: -0.47 for BCS1 versus BCS3 but no significance ( $p>0.05)$; -1.43 for BCS2 versus BCS3. These results showed that when the cows got fatter (From BCS1 or BCS2 to BCS3), they might get higher COD instead of IO. But the likelihood estimate was a positive value of 0.96 for BCS1 versus BCS2. When cows changed their BCS2 to BCS1, they would get COD instead of $\mathrm{IO}$, but it was significantly higher $(\mathrm{p}<0.05)$.

For Logit 3, the values of likelihood estimates were negative for BCS 1 versus BCS3 $(-0.43)$ but positive for BCS2 versus BCS3 (0.23), but both of these estimates were not statistically significant $(\mathrm{p}>0.05)$. The changes in BCS1 and BCS2 to BCS3 did not affect the risk of PCL versus COD. The likelihood estimate was -0.66 for BCS1 versus BCS2 indicates that when the cows change from BCS2 to BCS1, they will suffer from PCL instead of COD, but it was significantly lower $(\mathrm{p}<0.05)$.

The estimated odds ratio showed that the odds that the cows were suffered from PCL instead of IO was 0.41

Table 3. Maximum likelihood estimates and odds ratio of variables of different parities on categories of ovarian disorders (with reference variables as IO and COD in analyzed models)

\begin{tabular}{|c|c|c|c|c|c|c|c|c|c|c|}
\hline \multirow{3}{*}{ Logits } & \multirow{3}{*}{ Variables } & \multicolumn{4}{|c|}{ Maximum likelihood estimates } & \multicolumn{4}{|c|}{ Odds ratio } & \multirow{3}{*}{$\begin{array}{c}\text { Pr }> \\
\text { ChiSq }\end{array}$} \\
\hline & & \multirow{2}{*}{ Est } & \multirow{2}{*}{ SE } & \multicolumn{2}{|c|}{ CL95\% } & \multirow{2}{*}{$\begin{array}{l}\text { Odds } \\
\text { ratio }\end{array}$} & \multirow{2}{*}{$\mathrm{SE}_{\text {Odds }}$} & \multicolumn{2}{|c|}{ CL95\% } & \\
\hline & & & & Lower & Upper & & & Lower & Upper & \\
\hline \multirow{3}{*}{$\begin{array}{c}1 \\
(\mathrm{PCL} / \mathrm{IO})\end{array}$} & Par0 vs Par1 & -0.82 & 0.24 & -1.29 & -0.35 & 0.44 & 0.11 & 0.28 & 0.70 & 0.0006 \\
\hline & Par0 vs Par2 & -0.97 & 0.23 & -1.41 & -0.52 & 0.38 & 0.09 & 0.24 & 0.60 & $<.0001$ \\
\hline & Par1 vs Par2 & -0.15 & 0.17 & -0.48 & 0.19 & 0.86 & 0.15 & 0.62 & 1.21 & 0.3967 \\
\hline \multirow{3}{*}{$\begin{array}{c}2 \\
(\mathrm{COD} / \\
\mathrm{IO})\end{array}$} & Par0 vs Par1 & 0.06 & 0.32 & -0.57 & 0.68 & 1.06 & 0.34 & 0.57 & 1.98 & 0.8631 \\
\hline & Par0 vs Par2 & -0.30 & 0.29 & -0.87 & 0.28 & 0.74 & 0.22 & 0.42 & 1.32 & 0.3128 \\
\hline & Par1 vs Par2 & -0.35 & 0.26 & -0.87 & 0.17 & 0.70 & 0.19 & 0.42 & 1.18 & 0.1862 \\
\hline \multirow{3}{*}{$\begin{array}{c}3 \\
(\mathrm{PCL} / \\
\mathrm{COD})\end{array}$} & Par0 vs Par1 & -0.88 & 0.35 & -1.56 & -0.19 & 0.42 & 0.14 & 0.21 & 0.82 & 0.0118 \\
\hline & Par0 vs Par2 & -0.67 & 0.32 & -1.30 & -0.04 & 0.51 & 0.16 & 0.27 & 0.96 & 0.036 \\
\hline & Par1 vs Par2 & 0.20 & 0.27 & -0.32 & 0.73 & 1.23 & 0.33 & 0.73 & 2.07 & 0.4419 \\
\hline
\end{tabular}

Note: $\mathrm{PCL}=$ Persistent corpus luteum; $\mathrm{IO}=$ Inactive ovarian disease; $\mathrm{COD}=\mathrm{Cystic}$ ovarian disease; $\mathrm{SE}=\mathrm{Standard}$ errors of likelihood estimates; Par0= Parity 0 (Heifers); Par1= Parity 1; Par2= Pariy 2 and over; SE $=$ Standard errors of likelihood estimates; $S E=$ Standard errors of odds ratio estimates; CL95\%= Confident limits 95\%. 
times when changed from BCS3 to BCS1 and 0.30 times when changed from BCS3 to BCS2 $(p<0.05)$. The cows that were suffered from PCL were $59 \%$ significantly lower at BCS1 versus BCS3, or 70\% significantly lower at BCS2 versus BCS3. Therefore, when the cows got thinner, they tended to suffer from IO, and when they got fatter, they tended to suffer from PCL (Table 4, Logit 1).

The cows getting COD instead of IO were about 0.24 times when their BCS changed from BCS3 to BCS2. In other words, when the cows were in BCS2, the odds of suffering from COD instead of IO were $76 \%$ lower than cows in BCS3. Otherwise, the cows that suffered from COD instead of IO were about 2.62 times when their BCS changed from BCS2 to BCS1. But when their BCS changed from BCS2 to BCS1, they would suffer from PCL instead of COD that was about 0.52 times, or the cows suffering from PCL in BCS1 were $48 \%$ lower than BCS2 $(\mathrm{p}<0.05)$.

\section{The Effect of Housing Types}

The likelihood estimates explained that the cows were suffered from PCL instead of IO; from COD instead of IO were significantly lower $(p<0.05)$ when their houses were changed from well-invested to a simple type. But on the other side, they suffered from PCL instead of COD were significantly higher $(\mathrm{p}<0.05)$ when they were moved from well-invested to simple houses. When cattle were confined in simple houses, they tended to be suffered from IO, and in modern houses, they tended to get PCL or COD $(p<0.05)$. However, when compared between PCL and COD, the cattle kept in simple houses, tended to get PCL, and cattle kept in well-invested type tended to get COD (Table 5).

The odds ratio estimates indicated that when the cows were moved from well-invested to simple houses, the odds for the cows got PCL instead of IO was about 0.36 times, or the number of cattle kept in simple houses that tended to be suffered from PCL was 64\% lower compared to when they were kept in well-invested houses. The odds for the cows housed in simple type got COD instead of IO was about 0.17 times, or the cattle got COD instead of IO were $83 \%$ lower than they kept in well-invested houses. The odds for the cows got PCL instead of COD was about 2.07 times when they were kept in simple housing types versus in well-invested types $(\mathrm{p}<0.05)$.

Table 4. Maximum likelihood estimates and odds ratio of variables of different BCS on categories of ovarian disorders (with reference variables as IO and COD in analyzed models)

\begin{tabular}{|c|c|c|c|c|c|c|c|c|c|c|}
\hline \multirow{3}{*}{ Logits } & \multirow{3}{*}{ Variables } & \multicolumn{4}{|c|}{ Maximum likelihood estimates } & \multicolumn{4}{|c|}{ Odds ratio } & \multirow{3}{*}{$\begin{array}{c}\operatorname{Pr}> \\
\text { ChiSq }\end{array}$} \\
\hline & & \multirow{2}{*}{ Est } & \multirow{2}{*}{ SE } & \multicolumn{2}{|c|}{ CL95\% } & \multirow{2}{*}{$\begin{array}{l}\text { Odds } \\
\text { ratio }\end{array}$} & \multirow{2}{*}{$\mathrm{SE}_{\text {Odds }}$} & \multicolumn{2}{|c|}{ CL95\% } & \\
\hline & & & & Lower & Upper & & & Lower & Upper & \\
\hline \multirow{3}{*}{$\begin{array}{c}1 \\
(\mathrm{PCL} / \mathrm{IO})\end{array}$} & BCS1 vs BCS3 & -0.90 & 0.38 & -1.64 & -0.16 & 0.41 & 0.15 & 0.19 & 0.85 & 0.0172 \\
\hline & BCS2 vs BCS3 & -1.21 & 0.33 & -1.86 & -0.56 & 0.30 & 0.10 & 0.16 & 0.57 & 0.0003 \\
\hline & BCS1 vs BCS2 & 0.31 & 0.23 & -0.15 & 0.77 & 1.36 & 0.32 & 0.86 & 2.15 & 0.1917 \\
\hline \multirow{3}{*}{$\begin{array}{c}2 \\
(\mathrm{COD} / \\
\mathrm{IO})\end{array}$} & BCS1 vs BCS3 & -0.47 & 0.46 & -1.37 & 0.43 & 0.63 & 0.29 & 0.25 & 1.53 & 0.3051 \\
\hline & BCS2 vs BCS3 & -1.43 & 0.42 & -2.26 & -0.61 & 0.24 & 0.10 & 0.10 & 0.54 & 0.0006 \\
\hline & BCS1 vs BCS2 & 0.96 & 0.29 & 0.39 & 1.54 & 2.62 & 0.77 & 1.47 & 4.67 & 0.001 \\
\hline \multirow{3}{*}{$\begin{array}{c}3 \\
(\mathrm{PCL} / \\
\text { COD) }\end{array}$} & BCS1 vs BCS3 & -0.43 & 0.42 & -1.26 & 0.40 & 0.65 & 0.28 & 0.28 & 1.49 & 0.3097 \\
\hline & BCS2 vs BCS3 & 0.23 & 0.38 & -0.52 & 0.97 & 1.26 & 0.48 & 0.60 & 2.65 & 0.5491 \\
\hline & BCS1 vs BCS2 & -0.66 & 0.30 & -1.26 & -0.06 & 0.52 & 0.16 & 0.28 & 0.94 & 0.0308 \\
\hline
\end{tabular}

Note: $\mathrm{PCL}=$ Persistent corpus luteum; $\mathrm{IO}=$ Inactive ovarian disease; $\mathrm{COD}=\mathrm{Cystic}$ ovarian disease; $\mathrm{SE}=\mathrm{Odtandard}$ errors of estimated odds rasio; $\mathrm{BCS}=$ Body condition score; $\mathrm{SE}=$ Standard errors of likelihood estimates; $\mathrm{SE}$ Odds $=$ Standard errors of odds rasio; CL95\%= Confident limits $95 \%$.

Table 5. Maximum likelihood estimates and odds ratio of variables of different housing types on categories of ovarian disorders (with referent dependent variables as IO and COD in analyzed models)

\begin{tabular}{|c|c|c|c|c|c|c|c|c|c|c|}
\hline \multirow{3}{*}{ Logits } & \multirow{3}{*}{ Variables } & \multicolumn{4}{|c|}{ Maximum likelihood estimates } & \multicolumn{4}{|c|}{ Odds ratio } & \multirow{3}{*}{$\begin{array}{c}\operatorname{Pr}> \\
\text { ChiSq }\end{array}$} \\
\hline & & \multirow{2}{*}{ Est } & \multirow{2}{*}{ SE } & \multicolumn{2}{|c|}{ CL95\% } & \multirow{2}{*}{$\begin{array}{l}\text { Odds } \\
\text { ratio }\end{array}$} & \multirow{2}{*}{$\mathrm{SE}_{\text {Odds }}$} & \multicolumn{2}{|c|}{ CL95\% } & \\
\hline & & & & Lower & Upper & & & Lower & Upper & \\
\hline $\begin{array}{c}1 \\
(\mathrm{PCL} / \mathrm{IO})\end{array}$ & $\begin{array}{l}\text { Simple types versus } \\
\text { Well-invested types }\end{array}$ & -1.03 & 0.23 & -1.48 & -0.58 & 0.36 & 0.08 & 0.23 & 0.56 & $<.0001$ \\
\hline $\begin{array}{c}2 \\
(\mathrm{COD} / \\
\mathrm{IO})\end{array}$ & $\begin{array}{l}\text { Simple types versus } \\
\text { Well-invested types }\end{array}$ & -1.76 & 0.31 & -2.36 & -1.15 & 0.17 & 0.05 & 0.09 & 0.32 & $<.0001$ \\
\hline $\begin{array}{c}3 \\
(\mathrm{PCL} / \\
\mathrm{COD})\end{array}$ & $\begin{array}{l}\text { Simple types versus } \\
\text { Well-invested types }\end{array}$ & 0.73 & 0.32 & 0.1 & 1.35 & 2.07 & 0.66 & 1.1 & 3.87 & 0.0235 \\
\hline
\end{tabular}

Note: $\mathrm{PCL}=$ Persistent corpus luteum; $\mathrm{IO}=$ Inactive ovarian disease; $\mathrm{COD}=\mathrm{Cystic}$ ovarian disease; $\mathrm{SE}$ Odds $=\mathrm{Standard}$ errors of estimated odds rasio; $\mathrm{SE}=$ Standard errors of likelihood estimates; $\mathrm{SE}=$ Standard errors of estimated odds rasio; $\mathrm{SE}_{\mathrm{Odds}}=\mathrm{Standard}$ errors of odds rasio; CL95\%= Confident limits $95 \%$. 


\section{The Effects of Bedding Material Types}

The results indicated that all $P$-values for likelihood estimates were less than a significant level of 0.05 . These estimates showed that the differences in bedding materials had significant relations to ovarian disorders in cows. The cows suffering from PCL instead of IO were significantly lower for the cows used rubber bedding material compared to those used concrete bedding material $(\mathrm{p}<0.05)$; the number of cows suffering COD instead of IO were significantly lower when they stayed on the bedding material with rubber versus the bedding without using rubber $(p<0.05)$. In contrast, when the bedding material was changed from concrete to rubber, the number of cows that tended to get PCL instead of COD was significantly higher $(p<0.05)$. When the cattle were laid in rubber bedding material, they got the odds of suffering from $\mathrm{IO}$, and when they were laid in concrete bedding material, they got the odds of suffering from PCL or COD (in Logit1 and Logit2). However, they got a higher chance odds of suffering from PCL than COD when they laid in concrete bedding material (in Logit3) (Table 6).

The odds ratio estimates showed that the odds for cattle getting laid in rubber bedding material suffering from PCL instead of IO was 0.29 times versus laying in concrete bedding material, or the incidence of getting PCL in cattle laying on rubber bedding material was $71 \%$ lower than cattle laying on concrete bedding material (Logit1, Table 11); the odds for cattle got laid in rubber bedding material suffering from PCL instead of IO was 0.09 times compared when they got laid in concrete bedding material, or the incidence of getting PCL of cattle laying on rubber bedding material was 91\% lower than cattle standing on concrete bedding material (Logit2 Table 6). In contrast, the odds for cattle who got laid in rubber bedding material suffering from PCL instead of COD was 3.26 times, versus those laid in concrete bedding material (Logit3, Table 6).

\section{DISCUSSION}

In our research, dairy cattle raised in various regions got the odds of suffering differently from ovarian dysfunctions, which was quite similar to the finding that the cows reared in different latitudes had the risk of COD (Nelson et al., 2010). Otherwise, in this research, the cows got the odds of suffering from PCL in old age and got the odds of suffering from IO, or COD at the age of heifers.

Most of the elder cows were multiparous cows with induced uterus hypotonia, preventing the cervix from closing completely after delivery. Therefore, bacteria could easily enter the uterus, increasing the risk of metritis and reduce reproductive competence (Boer et al., 2016) by interrupting the secretion of PGF2 $\alpha$ in the uterus. This condition may decrease the ability to disrupt the corpus luteum that eventually increases the risk of PCL. In the North of Vietnam, heifer often get lack the attention of farmers, and poor nutrition can cause hormonal imbalances in the reproductive axis (hypothalamus-pituitary-ovary gland), which may be the cause of COD (Hanzen et al., 2007) due to the inhibition of GnRH synthesis in the hypothalamus or/and LH (López-Helguera et al., 2016).

However, these results have differed from some other results. Many other researchers reported that the cows in higher parity had an increased risk of being diagnosed with COD (Lee \& Kim, 2006; Nelson et al., 2010; Vercouteren et al., 2015; Pesantez et al., 2016). Moreover, no associations of COD were found with age, parity group, milk production, dystocia, uterine disease, BCS, or abortion. On the other hand, clinical mastitis was significantly related to the incidence of COD (Cattaneo et al., 2014). In the results, Hombegowda et al. (2019) reported that the age, parity, and BCS of the animal influence cystic ovarian diseases' risk factors.

The incidence of ovarian cysts was the highest in the cows having good body condition scoring (BCS-3), followed by cows having a very good BCS (3.5), followed by fat cows (BCS-4), and the least was found in animals having BCS 2 and 5 (Hombegowda et al., 2019).

Some researchers also reported housing type related to ovarian dysfunction of dairy cattle. In our research, the results indicated that the cattle confined in simple housing type tended to get the odds of suffering from $\mathrm{IO}$, and when they were kept in well-invested housing type, they tended to get the odds of suffering from PCL. In the other research, the cows' fertility kept in free-stalls was better, and cystic ovaries were lower than the cows kept in tie-stalls (Simensen et al., 2010). There have been few kinds of research about the risk

Table 6. Maximum likelihood estimates and odds ratio of variables of different bedding types on categories of ovarian disorders (with reference variables as $\mathrm{IO}$ and COD in analyzed models)

\begin{tabular}{|c|c|c|c|c|c|c|c|c|c|c|}
\hline \multirow{3}{*}{ Logits } & \multirow{3}{*}{ Variables } & \multicolumn{4}{|c|}{ Maximum likelihood estimates } & \multicolumn{4}{|c|}{ Odds ratio } & \multirow{3}{*}{$\begin{array}{c}\mathrm{Pr}> \\
\text { ChiSo }\end{array}$} \\
\hline & & \multirow{2}{*}{ Est } & \multirow{2}{*}{ SE } & \multicolumn{2}{|c|}{ CL95\% } & \multirow{2}{*}{$\begin{array}{l}\text { Odds } \\
\text { ratio }\end{array}$} & \multirow{2}{*}{$\mathrm{SE}_{\text {Odds }}$} & \multicolumn{2}{|c|}{ CL95\% } & \\
\hline & & & & Lower & Upper & & & Lower & Upper & \\
\hline $\begin{array}{c}1 \\
(\mathrm{PCL} / \mathrm{IO})\end{array}$ & Rubber vs Concrete & -1.24 & 0.22 & -1.68 & -0.81 & 0.29 & 0.06 & 0.19 & 0.44 & $<.0001$ \\
\hline$\stackrel{2}{2}(\mathrm{COD} / \mathrm{IO})$ & Rubber vs Concrete & -2.43 & 0.35 & -3.12 & -1.73 & 0.09 & 0.03 & 0.04 & 0.18 & $<.0001$ \\
\hline $\begin{array}{c}3 \\
\text { (PCL /COD) }\end{array}$ & Rubber vs Concrete & 1.18 & 0.36 & 0.47 & 1.9 & 3.26 & 1.19 & 1.6 & 6.67 & 0.0012 \\
\hline
\end{tabular}

Note: $\mathrm{PCL}=$ Persistent corpus luteum; $\mathrm{IO}=$ Inactive ovarian disease; $\mathrm{COD}=\mathrm{Cystic}$ ovarian disease; $\mathrm{SE}$ $\mathrm{SE}=$ Standard errors of likelihood estimates; SEOdds= Standard errors of estimated odds rasio; $\mathrm{SE}$ Odds $=$ Standard errors of odds rasio; CL95\%= Confident limits $95 \%$. 
of floor bedding on ovarian disorder, but the effects of stall type and bedding materials on lameness were found by Kara et al. (2011). Lying times on bedded mats indicated that mats were comfortable for the cows. Cows preferred stalls with rubber mats to stalls with a concrete floor since rubber mats may help maintain cow comfort (Norring et al., 2010). The reproductive performance of dairy animals also depends on floor type. In most dairy farms, reduced reproductive efficiency and culling problems have been observed due to lameness. With some bedding materials in free-stall houses, fertility was better compared to tie-stall houses (Nogalski, 2006). Similarly, dairy animals' housing in compost bedded packs resulted in the reduction in calving interval, days open, and higher milk production than convenient bedding housing (Black et al., 2013). In straw used calving pen, subclinical endometritis was $10.7 \%$ lower than other types of bedding like paper, sawdust, or sand (Cheong et al., 2011). Many researchers observed that rubber flooring is better for reproductive traits in dairy animals. Rubber flooring is better as compared to concrete for successful mounting during the estrus period. On the rubber floor, 2.3 mounts were observed during estrus than only 0.8 mounts on the concrete floor (Platz et al., 2008). Kara et al. (2015) reported that reproductive problems like repeat breeding, dystocia, and retained placenta were lowest in the rubber bedding than concrete and sand bedding.

In addition, rudimentary houses and hard concrete bedding had a negative impact on cow's hoof health (Franck \& De Belie, 2006), especially when maintaining cows at high ambient temperature and humidity can be stressful for cows. Stress can lead to plasma hormone secretion as catecholamines, glucocorticoids, and progesterone secretion from the adrenal gland. Increases cortisol level or adrenocorticotropic hormone or progesterone over the normal levels may also delay or inhibit GnRH and LH pulse secretions or alter normal follicular development, even COD disease (Noble et al., 2000).

\section{CONCLUSION}

Treatment of ovarian dysfunction could be more improved through knowledge and outstanding of the odds related to them. The changes of region, age classes, housing condition, body condition scores were associated with the odds for ovarian disorder categories of dairy cattle raising in Northern Vietnam.

\section{CONFLICT OF INTEREST}

None of the authors in this research has a financial or individual relationship with other persons or organizations that can unsuitably affect or bias the content of the research.

\section{ACKNOWLEDGEMENT}

The authors would like to express their deepest, most faithful thanks to the British Council for their funding and financial support. The thanks are also due to the Veterinary Faculty of National University of Agriculture; Official authorities at Agricultural Departments, and dairy farmers in Moc Chau District, Son La Province, Vinh Phuc Province, Ha Nam Province, Hanoi capital for their cooperation and kindness; especially cooperation and attempts from local veterinarians and technicians were greatly appreciated.

\section{REFERENCES}

Alawneh, J. I., M. A. Stevenson, N. B. Williamson, N. LopezVilallobos, \& T. Otley. 2012. The effect of live weight change on reproductive performance in a seasonally calving, pasture fed dairy herd. Livest. Sci. 145:131-139. https://doi.org/10.1016/j.livsci.2011.12.025

Black, R. A., J. L. D. G. B. Taraba, F. A. Damasceno, \& J. M. Bewley. 2013. Compost bedded pack dairy barn management, performance, and producer satisfaction. J. Dairy Sci. 96:8060-8074. https://doi.org/10.3168/jds.2013-6778

Cattaneo, L., M. L. Signorini, J. Bertoli, J. A. Bartolome, N. C. Gareis, P. U. Diaz, G. A. Bo, \& H. H. Ortega. 2014. Epidemiological description of cystic ovarian disease in Argentine dairy herds: Risk factors and effects on the reproductive performance of lactating cows. Reprod. Dom. Anim. 49:1028-1033. https://doi.org/10.1111/rda.12432

Cheong, S. H., D. V. Nydam, K. N. Galvão, B. M. Crosier, \& R. O. Gilbert. 2011. Cow-level \& herd-level risk factors for subclinical endometritis in lactating Holstein cows. J. Dairy Sci. 94:762-770. https://doi.org/10.3168/jds.2010-3439

De Boer, M. W., S. J. LeBlanc, J. Dubuc, S. Meier, W. Heuwieser, S. Arlt, R. O. Gilbert, \& S. McDougall. 2014. Invited review: Systematic review of diagnostic tests for reproductive-tract infection and inflammation in dairy cows. J. Dairy Sci. 97:3983-99. https://doi.org/10.3168/jds.2013-7450

Ferguson, J. 2017. Ovarian Dysfunction in Dairy Cows. WCDS Advances in Dairy Technology. 29:173-181.

Franck, A. \& N. De Belie. 2006. Concrete floor-bovine claw contact pressures related to floor roughness and deformation of the claw. J. Dairy Sci. 89:2952-2964. https://doi. org/10.3168/jds.S0022-0302(06)72567-X

Hombalegowda, H., N. Ramakrishnappa, N. K. Siddaraju, N. C. Sringeshwaraiah, \& S. Guelal. 2019. Factors influencing cystic ovarian disease in Holstein Friesian (HF) crossbred cattle. SSR Inst. Int. J. Life Sci. 5:2317-2321. https:// doi.org/10.21276/SSR-IIJLS.2019.5.3.6

Inchaisri, C., R. Jorritsma, P. L. A. M. Vos, G. C. van der Weijden, \& H. Hogeveen. 2010. Economic consequences of reproductive performance in dairy cattle. Theriogenology 74:835-846. https://doi.org/10.1016/j. theriogenology.2010.04.008

Kara, N. K., A. Galic, \& M. Koyuncu. 2011. Effects of stall type and bedding materials on lameness and hygiene score and effect of lameness on some reproductive problems in dairy cattle. J. Appl. Anim. Res. 39:334-338. https://doi.org/10.10 80/09712119.2011.607890

Kara, N. K., A. Galic, \& M. Koyucu. 2015. Comparison of milk yield and animal health in Turkish farms with differing stall types and resting surfaces. Asian-Australas. J. Anim. Sci. 28:268-272. https://doi.org/10.5713/ajas.14.0366

Klopčič M., A. Hamoen, \& J. Bewley. 2011. Body Condition Scoring of Dairy Cows. University of Ljubljana. Biotechnical Faculty, Department of Animal Science. Groblje 3, 1230 Domžale.

Lee, J. Y. \& I. H. Kim. 2006. Advancing parity is associated with high milk production at the cost of body condition and increased periparturient disorders in dairy herds. J. Vet. Sci. 7:161-166. https://doi.org/10.4142/jvs.2006.7.2.161.

Long, S. T. \& N. T. Thuy. 2017. Effects of metritis, hoof pathologies, parity and body condition score on postpartum 
ovarian function on dairy cow in Bavi, Hanoi. Journal of Animal Husbandry Sciences and Technics. 218:73-80.

Long, S. T. \& V. T. Phong. 2017. Using of Prostaglandin F2 $\alpha$ and Gonadotrophin Releasing Hormone in treatment of ovarian disorders in dairy herd in Vinh Phuc province. Journal of Animal Husbandry Sciences and Technics. 224:73-79.

López-Helguera I., M. G. Colazo, I. Garcia-Ispierto, \& F. LópezGatius. 2016. Factors associated with ovarian structures and intrauterine fluid in the postpartum period in dairy cows. J. Dairy Sci. 99:3925-3933. https://doi.org/10.3168/ jds.2015-10615

Luu, T. X., C. X. Dan, \& S. T. Long. 2014. Application of hormone in the treatment of ovarian disorder in dairy cattle in Bavi district, Ha noi, Vietnam. J. Biotechnol. 12:447-454.

Nelson, S. T., A. D. Martin, \& O. Østerås. 2010. Risk factors associated with cystic ovarian disease in Norwegian dairy cattle. Acta Vet. Scand. 52:60. https://doi. org/10.1186/1751-0147-52-60

Noble K. M., J. E. Tebble, D. Harvey, \& H. Dobson. 2000. Ultrasonography and hormone profiles of persistent ovarian follicles (cysts) induced with low doses of progesterone in cattle. J. Reprod. Fertil. 120:361-366. https://doi. org/10.1530/jrf.0.1200361

Nogalski, Z. 2006. Wpływ wydajności mleka krów na ich płodność w różnych systemach utrzymania (Effect of milk productivity on fertility in tied- and loose-housed cows). Acta Sci. Pol. Zootechnica. 5:97-106.

Norring, M., E. Manninen, A. M. de Passillé, J. Rushen, \& H. Saloniemi. 2010. Preferences of dairy cows for three stall surface materials with small amounts of bedding. J. Dairy Sci. 93:70-74. https://doi.org/10.3168/jds.2009-2164

Pesántez, J. L., O. Ortiz, \& J. Hernández-Cerón. 2016. Incidence of ovarian follicular cysts and their effect on reproductive performance in dairy cows: A case study in Mexico.
Arch. Med. Vet. 48:289-291. https://doi.org/10.4067/ S0301-732X2016000300007

Platz, S., F. Ahrens, J. Bendel, H. H. D. Meyer, \& M. H. Erhard. 2008. What happens with cow behavior when replacing concrete slatted floor by rubber coating: A case study. J. Dairy Sci. 91:999-1004. https://doi.org/10.3168/ jds.2007-0584

Santolaria, P., F. López-Gatius, J. A. Sánchez-Nadal, \& J. Yániz. 2012. Relationships between body weight and milk yield during the early postpartum period and bull and technician and the reproductive performance of high producing dairy cows. J. Reprod. Dev. 58:366-370. https://doi. org/10.1262/jrd.2011-035

Simensen, E., O. Østerås, K. E. Bøe, C. Kielland, L. E. Ruud, \& G. Næss. 2010. Housing system and herd size interactions in Norwegian dairy herds; associations with performance and disease incidence. Acta. Vet. Scand. 52:14. https://doi. org/10.1186/1751-0147-52-14

Vercouteren, M. M. A. A., J. H. J. Bittar, P. J. Pinedo, C. A. Risco, J. E. P., Santos, A. Vieira-Neto, \& K. N. Galvão. 2015. Factors associated with early cyclicity in postpartum dairy cows. J. Dairy Sci. 98:229-239. https://doi.org/10.3168/ jds.2014-8460

Walsh, S. W., E. J. Williams, \& A. C. Evans. 2011. A review of the causes of poor fertility in high milk producing dairy cows. Anim. Reprod. Sci. 123:127-138. https://doi.org/10.1016/j. anireprosci.2010.12.001

Yániz, J., F. López-Gatius, G. Bech-Sàbat, I. García-Ispierto, B. Serrano, \& P. Santolaria. 2008. Relationships between milk production, ovarian function and fertility in high-producing dairy herds in North-eastern Spain. Reprod. Domest. Anim. 43:38-43. https://doi. org/10.1111/j.1439-0531.2008.01227.x 